\title{
Studies on Thermal, Mechanical and Morphological Behaviour of Caprolactam Blocked Methylenediphenyl Diisocyanate and Bismaleimide Modified Epoxy Matrices
}

\author{
Daofang Shi \\ Tianjin Polytechnic University \\ NO.63 Cheng Lin Zhuang Road, Tianjin 300160, China \\ E-mail:sdf_1103@126.com \\ Mingkang An \\ Tianjin Polytechnic University \\ NO.63 Cheng Lin Zhuang Road, Tianjin 300160, China \\ E-mail:amk_8496@126.com \\ Guojun Wang \\ Tianjin Polytechnic University \\ NO.63 Cheng Lin Zhuang Road, Tianjin 300160, China \\ E-mail:wangguojun1001@163.com
}

\begin{abstract}
Diglycidyl ether of bisphenol A epoxy resin (DGEBA) was toughened with 5\%, 10\%and $15 \%$ (by wt) of caprolactam blocked methylenediphenyl diisocyanate (CMDI)using 4,4- diaminodiphenylmethane (DDM) as curing agent. The toughened epoxy resin was further modified with chemical modifier N, N'-bismaleimido-4, 40-diphenylmethane (BMI).Caprolactam blocked methylenediphenyl diisocyanate was synthesized by the reaction of caprolactam with methylenediphenyl diisocyanate in presence of carbon tetrachloride under nitrogen atmosphere. Thermal properties of the developed matrices were characterized by means of differential scanning calorimetry (DSC), thermo gravimetric analysis (TGA), heat distortion temperature (HDT) and dynamic mechanical analysis (DMA). Mechanical properties like tensile strength, flexural strength and impact strength were tested as per ASTM standards. The glass transition temperature (Tg) and thermal stability were decreased with increase in the percentage incorporation of CMDI. The thermomechanical properties of caprolactam blocked methylenediphenyl diisocyanate toughened epoxy resin were increased by increasing the percentage incorporation of bismaleimide. The values of impact strength for epoxy resin were increased with increase in the percentage concentration of CMDI. The homogeneous morphology of CMDI toughened epoxy resin and bismaleimide modified CMDI toughened epoxy resin system was ascertained from scanning electron microscope (SEM).
\end{abstract}

Keywords: Epoxy resin, CMDA, BMI, Glass transition temperature, Thermal stability and impact strength

\section{Introduction}

Epoxy resin is a versatile and widely accepted matrix material for the fabrication of advanced composites, hardware components, electronic circuit board materials, radomes and missile equipment components because of its excellent bonding, physic-chemical, thermal, mechanical, dielectric and aging characteristics(Leon Yu T,2000,p.257). To improve working performance of epoxy resin suitable for advanced engineering applications, the toughening of epoxy resin with by blending with flexible polymers and elastomers. However, they improved its impact properties with appreciable loss of tensile and thermal properties. Hence, selection of suitable polymeric materials is essential to 
improve the impact strength with retaining stiffness, glass transition temperature and thermal stability of the epoxy matrix.

In earlier studies the significant improvement in thermo mechanical, dielectric and aging characteristics have been achieved by using siloxane (Suresh Kumar R, 2006, p.668), cyanate ester (Dinakaran K, 2003, p.1596) and polysulphone (Rajasekaran R, 2007, p.911) as chemical modifiers for epoxy resin.

To make further advancement in this direction the present work is under taken to use caprolactam blocked methylenediphenyl diisocyanate as toughening agentand bismaleimide as chemical modifier for epoxy resin. Propriate chemical modifiers are essential. The toughness of the epoxy resin has been increased by blend

Caprolactam blocked methylenediphenyl diisocyanate isexpected to possess better combinations of thermo mechanical properties suitable for the fabrication of polymer composites because of their flexible structure (-NH-CO-) formed during in situ reaction of cyclic aliphatic caprolactam with aromatic diisocyanate. Several blocked diisocyanates like ketoxime, dimethylpyrazole and caprolactam blocked aromatic diisocyanates ( Subramani S, 2004, p.329) have already been developed and used for the synthesis of chain extended polyurethanes.

Blocked diisocyanate with flexible linkage (-NH-CO-) is expected to function as the best thermoplastic toughener for epoxy resin, because of its versatile behavior of flexibility. It was observed that the introduction of CMDI into epoxy resin improved its mechanical properties with little loss of glass transition temperature. To retain and to improve the glass transition temperature of CMDI (Han HL, 1998, p.2635) toughened epoxy system to an appreciable extent, bismaleimide (Guozheng Liang, 1998, p.1623) is used as a chemical modifier in the present work owing to its superior thermo mechanical properties.

Hence, in the present work an attempt has been made to improve both toughness and thermo mechanical behavior of epoxy resin without an appreciable loss in strength properties by forming an inter-crosslinked network of caprolactam blocked methylenediphenyl diisocyanate toughened epoxy system and bismaleimide (4,4'-bismaleimidodiphenylmethane).

\section{Experimental}

\subsection{Materials}

The commercially available epoxy resin (diglycidylether of bisphenol A, DGEBA) having epoxy equivalent about 180-190, 4, 4'-diaminodiphenylmethane (DDM) curing agent.. BMI was obtained from Hubei. CMDI was obtained from Shandong.

\subsection{Preparation of caprolactam blocked diisocyanate epoxy resin bismaleimide blend}

Fixed amount of epoxy resin, varying amounts $(5 \%, 10 \%$ and $15 \%)$ of caprolactam blocked methylenediphenyl diisocyanate (by wt $\%$ ) were thoroughly blended at $90{ }^{\circ} \mathrm{C}$ for $10 \mathrm{~min}$ with constant stirring. The calculated amounts $(4 \%$, $8 \%$ and $12 \%$ ) of BMI (by wt \%) were dissolved in the above blend at $100{ }^{\circ} \mathrm{Cunder}$ vigorous stirring. After complete dissolution, the stoichiometric amount of diaminodiphenylmethane (with respect to epoxy) was added and the

\subsection{Test methods}

\subsubsection{Thermal properties}

Glass transition temperature (Tg) of the samples wasdetermined using a DSC Netzsch (TA instruments, USA)in the temperature range between $50{ }^{\circ} \mathrm{Cand} 250{ }^{\circ} \mathrm{Cat}$ aheating rate of $10{ }^{\circ} \mathrm{Cper}$ min in nitrogen atmosphere. Thermo-gravimetric analysis (TGA) was carried out using a Thermal Analyst 2000 (TA instruments, USA) at a heating rate of $10^{\circ} \mathrm{Cper}$ min in nitrogen atmosphere. Dynamic mechanical behavior of the samples was measured using a DMA Netzsch 242 at a heating rate of $10^{\circ} \mathrm{Cper}$ min from 30 to $300^{\circ} \mathrm{C}$. The heat deflection temperature (HDT) of the samples was tested as per ASTM D648 - 72.

\subsubsection{Mechanical properties}

The tensile (stress-strain) properties were determined using INSTRON (Model 6025 UK) as per ASTM D 3039 at 10 $\mathrm{mm} / \mathrm{min}$ cross-head speed using specimen with a width of $25 \mathrm{~mm}$, length of $200 \mathrm{~mm}$ and thickness of $3 \mathrm{~mm}$. The flexural (strength and modulus) properties were measured (INSTRON, Model 6025 UK) as per ASTM D 790 using specimen with dimensions $3 \mathrm{~mm}$ in depth, $10 \mathrm{mmin}$ width and $90 \mathrm{~mm}$ in length at $10 \mathrm{~mm} / \mathrm{min}$ cross-head speed. The unnotched Izod impact strength of each sample was studied as per ASTM D 256. Five sample specimens were tested for each analysis.

\subsubsection{Morphology}

Surface morphology of fractured surface of the samples was performed using scanning electron microscope (SEM; JEOL JSM Model 6360). The fractured surface of the samples was coated with platinum before scanning. 


\section{Results and discussion}

\subsection{Thermal properties}

The glass transition temperature ( $\mathrm{Tg}$ ) of unmodified epoxy, caprolactam blocked methylenediphenyl diisocyanate toughened epoxy systems and bismaleimide incorporated caprolactam blocked methylenediphenyl diisocyanate toughened epoxy systems are presented in Table 1. The value of the glass transition temperature of the epoxy system is decreased with increasing concentration of caprolactam blocked methylenediphenyl diisocyanate. For example, the $\mathrm{Tg}$ values obtained for 5\%,10\% and $15 \%$ caprolactam blocked methylenediphenyl diisocyanate toughened epoxy systems are $162{ }^{\circ} \mathrm{C}, 154^{\circ} \mathrm{Cand} 148{ }^{\circ} \mathrm{C}$, respectively, when compared with that of $165^{\circ} \mathrm{Cobtained}$ for unmodified epoxy system. This may be explained due to the chain lengthening and flexibility behaviour of-NH-CO- linkage formed during the reaction of aliphatic cyclic caprolactam with aromatic diisocyanates, which in turn decreased the effective crosslink density. This creates excess free volume in the matrix system and leads to reduction in the values of $\mathrm{Tg}$, since $\mathrm{Tg}$ is associated with mobility of the molecules (Table 1) and which undergo co-operative motions i.e., segmental motion above $\mathrm{Tg}$. The introduction of bismaleimide into caprolactam blocked methylenediphenyl diisocyanate (CMDI) toughened epoxy systems has increased the values of Tg when compared to CMDI toughened epoxy systems. The values of $\mathrm{Tg}$ for $4 \%, 8 \%$ and $12 \%$ BMI incorporated $10 \%$ caprolactam blocked methylenediphenyl diisocyanate toughened epoxy system are increased to $160{ }^{\circ} \mathrm{C}, 168{ }^{\circ} \mathrm{Cand} 173{ }^{\circ} \mathrm{C}$, respectively(Table 1) when compared with CMDI toughened epoxy system without BMI incorporation. This may be explained due to the homopolymerization of BMIs rather than the Michael addition reaction confirmed from our earlier studies, since the Michael addition reaction reduces the crosslink density due to chain extension. The single Tg value obtained for both the BMI modified epoxy and CMDI toughened epoxy systems confirms the formation of intercrosslinking network between epoxy and caprolactam. The values of HDT obtained for epoxy, caprolactam blocked methylenediphenyl diisocyanate toughened epoxy systems are presented in Table 1. From Table 1, it is evident that the values of HDT are decreased with increasing caprolactam blocked methylenediphenyl diisocyanate concentration due to lowering crosslink density and in turn reduced the values of heat distortion temperature.

\subsection{Thermogravimetric analysis}

The incorporation of caprolactam blocked methylenediphenyl diisocyanate into epoxy resin decreased the thermal stability and lowered the degradation temperature according to the rise in percentage concentration (Table 2). For example, the temperature required for $20 \%, 40 \%$ and $60 \%$ weight losses of unmodified epoxy system are $375{ }^{\circ} \mathrm{C}$, $393{ }^{\circ} \mathrm{Cand} 422{ }^{\circ} \mathrm{C}$, respectively, whereas the temperatures required to attain the same percentages of weight losses for $10 \%$ caprolactam blocked methylenediphenyl diisocyanate toughened epoxy system are decreased to $352{ }^{\circ} \mathrm{C}$, $368{ }^{\circ} \mathrm{Cand} 392{ }^{\circ} \mathrm{C}$, respectively (Table2). A similar trend is observed for $5 \%$ and $15 \%$ CMDI toughened epoxy systems. This may be explained due to the presence of thermally weak flexible linkage (-NH-CO-) in the epoxy backbone. The introduction of bismaleimide into caprolactam blocked methylenediphenyl diisocyanate toughened epoxy system increased the degradation temperature. The temperatures required for $20 \%, 40 \%$ and $60 \%$ weight losses of $8 \%$ BMI incorporated $10 \%$ CMDI toughened epoxy system are increased to $383{ }^{\circ} \mathrm{C}, 413{ }^{\circ} \mathrm{Cand} 427{ }^{\circ} \mathrm{C}$, respectively, when compared to those of unmodified epoxy resin occurred at $375{ }^{\circ} \mathrm{C}, 393{ }^{\circ} \mathrm{C} \_\mathrm{C}$ and $422{ }^{\circ} \mathrm{C}$, respectively (Table 2). This is explained due to the formation of inter-crosslinking network between epoxy resin and bismaleimide and the rigid heterocyclic ring structure of bismaleimide.

\subsection{Mechanical properties}

The observed values for tensile and flexural properties of unmodified epoxy, caprolactam blocked methylenediphenyl diisocyanate toughened epoxy are presented in Table 3. The introduction of $5 \%, 10 \%$ and $15 \%$ caprolactam blocked methylenediphenyl diisocyanate (by wt $\%$ ) into epoxy resin enhanced the values of tensile strength by $3 \%, 12 \%, 20 \%$, respectively, when compared with that of unmodified epoxy resin. Similarly the values of flexural strength of 5\%, 10\% and $15 \%$ of CMDI blocked epoxy resin systems are increased to $4 \%, 13 \%$ and $20 \%$, respectively, when compared with that of unmodified epoxy system, due to the formation of an interpenetrating network between he molecular chains of epoxy and caprolactam blocked methylenediphenyl diisocyanate. Further, the incorporation of $4 \%, 8 \%, 12 \%$ bismaleimide into $10 \%$ CMDI toughened epoxy resin increased the values of tensile strength by $18 \%, 27 \%, 33 \%$, respectively, and flexural strength by $18 \%, 24 \%, 32 \%$, respectively, when compared with that of unmodified epoxy system due to the formation of the network structure between bismaleimide and epoxy resin. A trend similar to this was observed in the cases of tensile modulus and flexural modulus (Table 3).

The incorporation of 5\%,10\% and 15\% of CMDI into the epoxy system improved the impact strength to an appreciable extent by $23 \%, 59 \%, 74 \%$, respectively, when compared with that of unmodified epoxy system. The improvement in impact behaviour may be explained due to the influence of long molecular chain with flexible group (-NH-CO- present in the caprolactam blocked methylenediphenyl diisocyanate skeleton. In contrast, the incorporation of bismaleimide in both epoxy and caprolactam blocked methylenediphenyl diisocyanate toughened epoxy resin decreased the values of impact strength when compared with that of unmodified epoxy system and 10\% CMDI toughened epoxy resin. The 
decrease in the values of impact strength is due to the restricted chain mobility resulted from the formation of network structure and consequent reduction in free volume. However, a significant improvement in the values of impact strength $(51 \%, 46 \%$ and $36 \%$ ) is observed for $10 \%$ CMDI toughened epoxy system incorporated with $4 \%, 8 \%$ and $12 \%$ BMI when compared with that of unmodified epoxy system (Table 3). The mechanical properties of epoxy-BMI modified with different modifiers (DGTPDMS, PS and PES) are compared with BMI modified CMDI toughened epoxy system (Table $4 \mathrm{a}, \mathrm{b}$ and $\mathrm{c}$ ).

\subsection{Dynamic mechanical analysis}

The ability of a polymeric material to withstand load at elevated temperatures is one of the key aspects of thermomechanical behaviour required for high performance applications to be studied. Dynamic mechanical analysis is a method that measures the stiffness and mechanical damping of a cyclically deformed material as a function of temperature. The loss tangent is a sensitive indicator of crosslinking. At temperatures above $\mathrm{Tg}$, damping behavior decreases due to increase of crosslinking. Fig. 1 shows the tand curves of unmodified epoxy, caprolactam blocked methylenediphenyl diisocyanate toughened epoxy and BMI modified CMDI toughened epoxy systems at a heating rate of $10^{\circ} \mathrm{C}$ per min from 30 to $300^{\circ} \mathrm{C}$. The caprolactam blocked methylenediphenyl diisocyanate toughened epoxy system exhibited a higher tan $\mathrm{d}$ maximum value and storage modulus than unmodified epoxy resin. This indicated that the caprolactam blocked methylenediphenyl diisocyanate toughened epoxy system has lesser crosslink density than unmodified epoxy system; where as the incorporation of BMI into epoxy has decreased the tand maximum value and storage modulus, due to the increased crosslink density. This further supports the results obtained from thermal studies (Tg) (Fig.2).

\subsection{Morphology}

Scanning electron microscope was used to investigate the morphology of matrix systems (Fig. 3). SEM photographs of fractured surfaces of the unmodified epoxy and caprolactam blocked methylenediphenyl diisocyanate toughened epoxy resin systems indicated a smooth, glassy and homogeneous microstructure without any plastic deformation. The homogeneous morphology exhibited by the CMDI toughened epoxy system is due to the good compatibility and inter-crosslinking reaction between the caprolactam blocked methylenediphenyl diisocyanate and epoxy resin.

The SEM micrograph of the fractured surface of a BMI modified epoxy system is almost similar to that of the unmodified epoxy system. This indicates that there are no separate phase domains. Further, a smooth fractured surface is observed with increasing BMI content due to the brittle behavior imparted by BMI. The fractured surface of BMI modified CMDI toughened epoxy system showed a homogeneous morphology according to their percentage concentration.

\section{Conclusion}

BMI modified epoxy and caprolactam blocked methylenediphenyl diisocyanate toughened epoxy intercrosslinked network with various concentrations of BMI and CMDI were developed. Thermal properties such as glass transition temperature, heat distortion temperature and thermal stability of BMI modified epoxy and caprolactam blocked methylenediphenyl diisocyanate toughened epoxy matrices were compared with that of unmodified epoxy system. The caprolactam blocked methylenediphenyl diisocyanate toughened epoxy system possessed decreased thermal stability, glass transition temperature and heat distortion temperature. The incorporation of bismaleimide into caprolactam blocked methylenediphenyl diisocyanate toughened epoxy has increased the thermal properties such as thermal stability, heat distortion temperature and glass transition temperature. From the data obtained from thermal analysis, it was observed that the BMI homopolymerization reaction predominates over the Michael addition reaction. Data resulted from mechanical studies indicated that the incorporation of caprolactam blocked methylenediphenyl diisocyanate into epoxy, improved the tensile and flexural properties with appreciable extent in impact behavior. Similarly, the incorporation of BMI also increased the tensile and flexural properties according to its percentage content with a little loss in the values of impact strength. The incorporation of CMDI into epoxy increased the water absorption when compared with unmodified epoxy system but decreased in the case of BMI incorporated CMDI toughened epoxy systems. The morphology study indicated that BMI modified epoxy systems showed homogenous microstructure without any plastic deformation. The BMI/CMDI modified epoxy matrix systems possess better thermal stability, dynamic mechanical behavior and better resistance than that of the unmodified epoxy system. These toughened epoxy matrix systems could be used to fabricate advanced composite components of improved toughness with better thermo mechanical behavior for engineering applications.

\section{References}

Dinakaran.K,Suresh Kumar.R,and Alagar M. (2003). Preparation and characterization of bismaleimide-modified bisphenol dicyanate epoxy matrices. J Appl Polym Sci, 90, 1596-1603.

Han, HL, and Li, KY. (1998). Interpenetrating polymer networks of bismaleimide and polyether polyurethane-crosslinked epoxy. J Appl Polym Sci, 70, 2635-2645. 
Leon Yu T. and Chen Y.S. (2000). Physical aging of epoxy resin blended with poly(ether sulfone): effect of poly(ether sulfone) molecular weight. $J$ Polym Re. s, 7, 257-266.

Liang, Guozheng, and Fan, Jing. (1999). Novel modified bismaleimide resins with improved ablativity. J Appl Polym Sci, 73, 1623-1631.

Rajasekaran R,and Alagar M. (2007). Mechanical properties of bismaleimides modified polysulfone epoxy matrices. Int J Polym Mater, 56, 911-27.

Subramani S, Cheong .I.W,and Kim. J.H.(2004). Chain extension studies of waterborne polyurethanes from methyl ethyl ketoxime/e-caprolactamblocked aromatic isocyanates. Prog Org Coat, 51, 329-338.

Suresh Kumar R.and Alagar M.(2006). Studies on mechanical, thermal and morphological of diglycidylether terminated polydimethylsiloxane modified epoxy-bismaleimide matrices. J Appl Polym Sc, 101, 668-74.

Table 1. Thermal and water absorption behavior of BMI modified CMDI toughened epoxy hybrid matrices

\begin{tabular}{cccc}
\hline $\begin{array}{c}\text { Epoxy/CMDI/BMI } \\
\text { composition }\end{array}$ & $\begin{array}{c}\text { Heat distortion } \\
\text { temperature }\left({ }^{\circ} \mathrm{C}\right)\end{array}$ & $\begin{array}{c}\text { Glass transition } \\
\text { temperature }\left({ }^{\circ} \mathrm{C}\right)\end{array}$ & $\begin{array}{c}\text { Glass transition } \\
\text { temperature }\left({ }^{\circ} \mathbf{C}\right) \\
\text { from } D S C\end{array}$ \\
\hline $100 / 00 / 00$ & 154 & 165 & 165 \\
$100 / 05 / 00$ & 150 & 162 & 163 \\
$100 / 10 / 00$ & 146 & 154 & 154 \\
$100 / 15 / 00$ & 142 & 148 & 149 \\
$100 / 00 / 04$ & 157 & 167 & 168 \\
$100 / 00 / 08$ & 161 & 172 & 171 \\
$100 / 00 / 12$ & 170 & 180 & 182 \\
$100 / 10 / 04$ & 151 & 160 & 162 \\
$100 / 10 / 08$ & 159 & 168 & 170 \\
$100 / 10 / 12$ & 163 & 173 & 172 \\
\hline
\end{tabular}


Table 2. Data on thermal stability BMI modified CMDI toughened epoxy hybrid matrices

\begin{tabular}{ccccc}
\hline $\begin{array}{c}\text { Epoxy/CMDI/BMI } \\
\text { composition }\end{array}$ & $\begin{array}{c}\text { Initial } \\
\text { decomposition } \\
\text { temperature }\left({ }^{\circ} \mathrm{C}\right)\end{array}$ & \multicolumn{2}{l}{ Temperature at characteristic weight loss $\left({ }^{\circ} \mathbf{C}\right)$} \\
\cline { 3 - 4 } $100 / 00 / 00$ & 355 & 375 & $40 \%$ & $60 \%$ \\
$100 / 05 / 00$ & 348 & 369 & 393 & 422 \\
$100 / 10 / 00$ & 341 & 352 & 380 & 408 \\
$100 / 15 / 00$ & 332 & 343 & 368 & 392 \\
$100 / 00 / 04$ & 364 & 391 & 357 & 377 \\
$100 / 00 / 08$ & 372 & 398 & 411 & 428 \\
$100 / 00 / 12$ & 383 & 408 & 421 & 436 \\
$100 / 10 / 04$ & 349 & 366 & 433 & 445 \\
$100 / 10 / 08$ & 356 & 383 & 388 & 407 \\
$100 / 10 / 12$ & 367 & 394 & 413 & 427 \\
\hline
\end{tabular}

Table 3. Mechanical properties of BMI modified CMDI toughened epoxy hybrid matrices

\begin{tabular}{llllll}
\hline $\begin{array}{l}\text { Epoxy/CMDI/BMI } \\
\text { composition }\end{array}$ & $\begin{array}{l}\text { Tensile } \\
\text { strength } \\
(\text { MPa })\end{array}$ & $\begin{array}{l}\text { Tensile } \\
\text { modulus } \\
(\text { MPa })\end{array}$ & $\begin{array}{l}\text { Flexural } \\
\text { strength } \\
(\text { MPa })\end{array}$ & $\begin{array}{l}\text { Flexural } \\
\text { modulus } \\
(\text { MPa })\end{array}$ & $\begin{array}{l}\text { Impact } \\
\text { strength } \\
(\mathbf{J} / \mathbf{m})\end{array}$ \\
\hline $100 / 00 / 00$ & $66 \pm 6$ & $2753 \pm 39$ & $115 \pm 4$ & $1984 \pm 31$ & $105 \pm 3$ \\
$100 / 05 / 00$ & $68 \pm 4$ & $2770 \pm 28$ & $120 \pm 6$ & $2071 \pm 22$ & $129 \pm 5$ \\
$100 / 10 / 00$ & $74 \pm 7$ & $2863 \pm 21$ & $130 \pm 2$ & $2162 \pm 18$ & $167 \pm 4$ \\
$100 / 15 / 00$ & $79 \pm 3$ & $2912 \pm 23$ & $138 \pm 7$ & $2210 \pm 26$ & $183 \pm 2$ \\
$100 / 05 / 04$ & $73 \pm 3$ & $2974 \pm 23$ & $128 \pm 3$ & $2143 \pm 23$ & $126 \pm 4$ \\
$100 / 05 / 08$ & $80 \pm 4$ & $3088 \pm 14$ & $137 \pm 1$ & $2247 \pm 18$ & $121 \pm 2$ \\
$100 / 05 / 12$ & $85 \pm 7$ & $3194 \pm 27$ & $147 \pm 7$ & $2335 \pm 44$ & $115 \pm 7$ \\
$100 / 10 / 04$ & $78 \pm 2$ & $3053 \pm 33$ & $136 \pm 3$ & $2198 \pm 19$ & $159 \pm 4$ \\
$100 / 10 / 08$ & $84 \pm 4$ & $3164 \pm 24$ & $143 \pm 4$ & $2283 \pm 27$ & $153 \pm 2$ \\
$100 / 10 / 12$ & $88 \pm 7$ & $3260 \pm 28$ & $152 \pm 2$ & $2386 \pm 12$ & $143 \pm 7$ \\
$100 / 15 / 0$ & $81 \pm 3$ & $43117 \pm 23$ & $144 \pm 3$ & $2237 \pm 33$ & $177 \pm 4$ \\
$100 / 15 / 08$ & $86 \pm 6$ & $3221 \pm 14$ & $150 \pm 5$ & $2318 \pm 14$ & $169 \pm 2$ \\
$100 / 15 / 12$ & $91 \pm 2$ & $3314 \pm 18$ & $157 \pm 2$ & $2424 \pm 28$ & $160 \pm 7$ \\
$100 / 00 / 04$ & $71 \pm 5$ & $2920 \pm 17$ & $123 \pm 3$ & $2091 \pm 14$ & $96 \pm 6$ \\
$100 / 00 / 08$ & $77 \pm 8$ & $3026 \pm 22$ & $131 \pm 2$ & $2206 \pm 23$ & $91 \pm 4$ \\
$100 / 00 / 12$ & $83 \pm 3$ & $3144 \pm 27$ & $143 \pm 4$ & $2307 \pm 29$ & $86 \pm 7$ \\
\hline
\end{tabular}


Table 4a. Epoxy modifications using different modifiers - a comparison

\begin{tabular}{llll}
\hline $\begin{array}{l}\text { Polymer systems } \\
(100 / 10 / 12)\end{array}$ & $\begin{array}{l}\text { Tensile } \\
\text { strength }(\mathrm{MPa})\end{array}$ & $\begin{array}{l}\text { Flexural } \\
\text { strength }(\mathrm{MPa})\end{array}$ & $\begin{array}{l}\text { Impact } \\
\text { strength } \mathbf{( J / m )}\end{array}$ \\
\hline Epoxy/CMDI/BMI & $88 \pm 7$ & $152 \pm 2$ & $143 \pm 7$ \\
Epoxy/DGTPDMS/ & $71 \pm 3$ & $97 \pm 5$ & $96 \pm 1$ \\
BMI & $70 \pm 4$ & $124 \pm 5$ & $119 \pm 3$ \\
Epoxy/PS/BMI & $70 \pm 5$ & $119 \pm 5$ & $120 \pm 7$ \\
Epoxy/PES/BMI & & & \\
\hline
\end{tabular}

CMDI - Caprolactam blocked methylenediphenyl diisocyanate.

DGTPDMS - Diglycidyl ether terminated poly(dimethyl siloxane).

PS - Polysulfone.

PES - Polyethersulfone.

Table 4b. Epoxy modifications using different modifiers - a compariso

\begin{tabular}{lll}
\hline $\begin{array}{l}\text { Polymer systems } \\
(100 / 10 / 12)\end{array}$ & $\begin{array}{l}\text { Heat Distortion } \\
\text { Temperature } \\
\left({ }^{\circ} \mathrm{C}\right)\end{array}$ & $\begin{array}{l}\text { Glass transition } \\
\text { temperature } \\
\left({ }^{\circ} \mathbf{C}\right)\end{array}$ \\
\hline Epoxy/CMDI/BMI & 163 & 173 \\
Epoxy/DGTPDMS/BMI & 155 & 167 \\
Epoxy/PES/BMI & 157 & 179 \\
\hline
\end{tabular}

Table 4c. Epoxy modifications using different modifiers - a comparison

\begin{tabular}{|c|c|c|c|c|}
\hline \multirow[t]{2}{*}{$\begin{array}{c}\text { Polymer systems } \\
(100 / 10 / 12)\end{array}$} & \multirow[t]{2}{*}{$\begin{array}{c}\text { Initial decomposition } \\
\text { temperature (_C) }\end{array}$} & \multicolumn{3}{|c|}{$\begin{array}{c}\text { Temperature at } \\
\text { characteristic } \\
\text { weight loss }\left({ }^{\circ} \mathrm{C}\right)\end{array}$} \\
\hline & & $20 \%$ & $40 \%$ & $60 \%$ \\
\hline Epoxy/CMDI/BMI & 367 & 394 & 426 & 433 \\
\hline Epoxy/DGTPDMS/BMI & 380 & 414 & 454 & 470 \\
\hline Epoxy/PES/BMI & 347 & 378 & 412 & 426 \\
\hline
\end{tabular}

CMDI - caprolactam blocked methylenediphenyl diisocyanate.

DGTPDMS - diglycidyl ether terminated poly(dimethyl siloxane).

PS - polysulfone.

PES - polyethersulfone. 


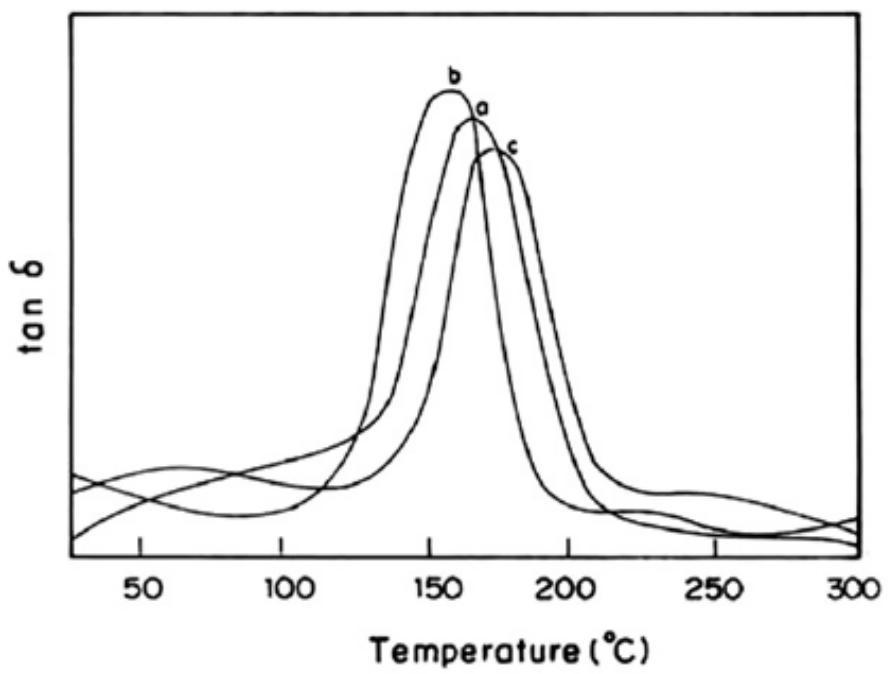

Figure 1. Variation of tand as a function of temperature (a) unmodified epoxy, (b) caprolactam blocked methylenediphenyl diisocyanate (10\%)toughened epoxy system and (c) bismaleimide (8\%) modified caprolactamblocked methylenediphenyl diisocyanate $(10 \%)$ toughened epoxy system.

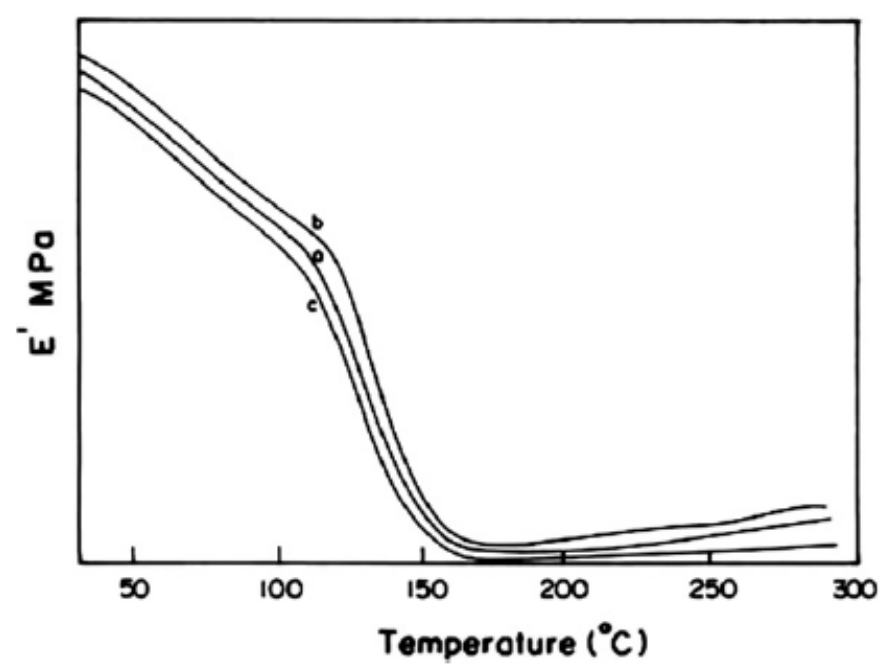

Figure 2. Variation of storage modulus as a function of temperature (a) unmodified epoxy, (b) caprolactam blocked methylenediphenyl diisocyanate (10\%) toughened epoxy system and (c) bismaleimide (8\%) modified caprolactam blocked methylenediphenyl diisocyanate $(10 \%)$ toughened epoxy system. 

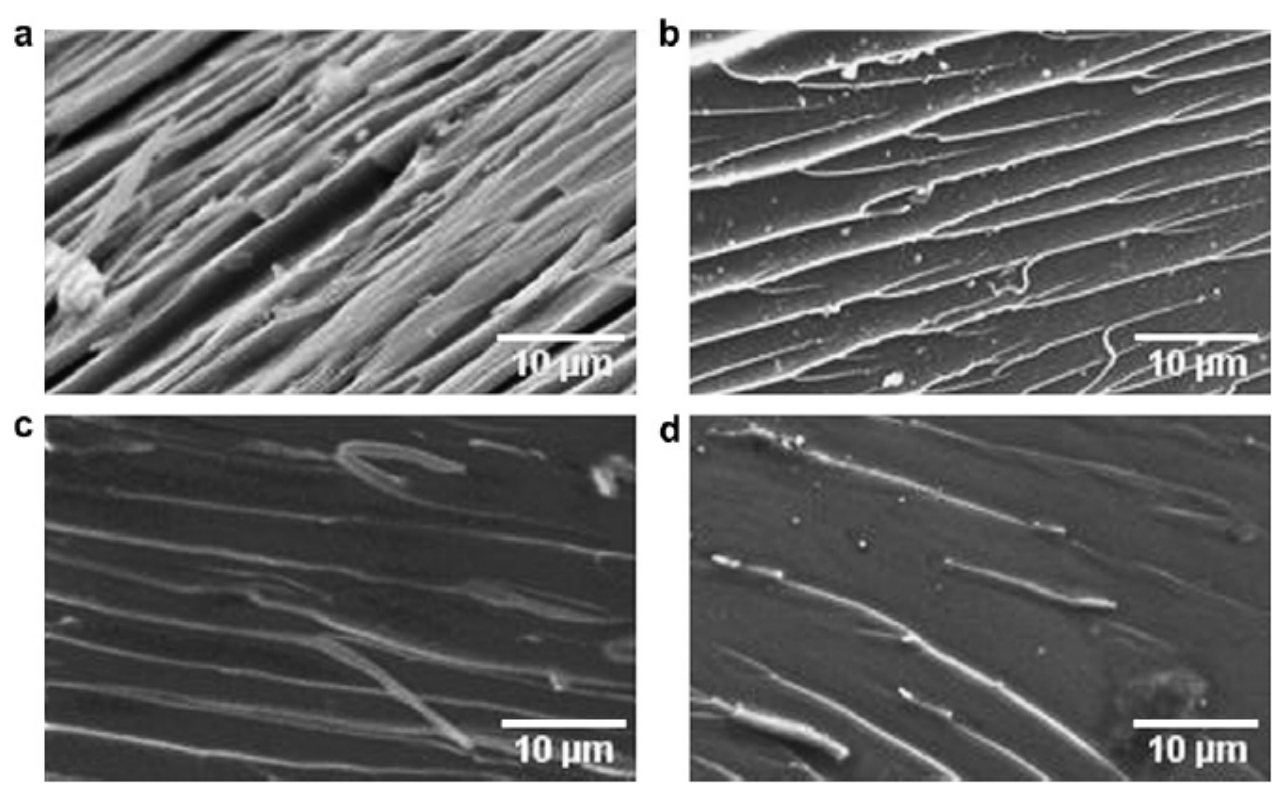

Figure 3. SEM micrographs of (a) unmodified epoxy, (b) caprolactam blocked methylenediphenyl diisocyanate (10\%) toughened epoxy system, (c)bismaleimide (8\%) modified epoxy system and (d) bismaleimide (8\%) modified caprolactam blocked methylenediphenyl diisocyanate (10\%) toughened epoxy system. 